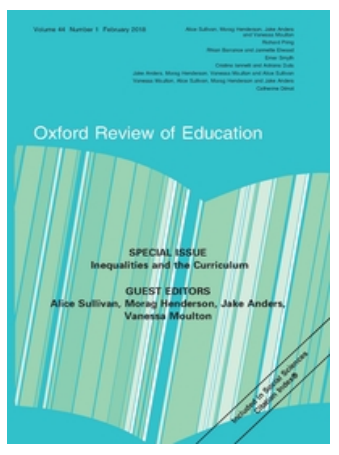

Oxford Review of Education

\title{
Inequalities and the curriculum
}

\section{Alice Sullivan, Morag Henderson, Jake Anders \& Vanessa Moulton}

To cite this article: Alice Sullivan, Morag Henderson, Jake Anders \& Vanessa Moulton (2018) Inequalities and the curriculum, Oxford Review of Education, 44:1, 1-5, DOI: 10.1080/03054985.2018.1409961

To link to this article: https://doi.org/10.1080/03054985.2018.1409961

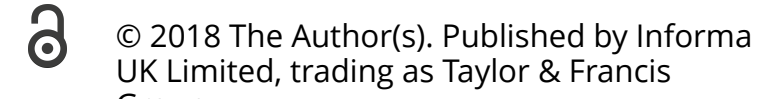
Group

曲 Published online: 12 Feb 2018.

Submit your article to this journal

Q View related articles $\sqsubset$

View Crossmark data \lceil 


\title{
Inequalities and the curriculum
}

\author{
Alice Sullivan (D), Morag Henderson (D), Jake Anders (D) and Vanessa Moulton (D) \\ UCL Institute of Education, UK
}

Theoretical and epistemological debates on the school curriculum are of longstanding interest within the sociology and philosophy of education. Strong views have been, and continue to be, asserted regarding the fairness of particular curricula for disadvantaged groups, and working class pupils in particular (Pring, 1972; Simon, 1976; Young, 1971, 1999). Yet, until recently, there has been a stark lack of empirical evidence to inform the theoretical debate on the school curriculum. While the importance of 'horizontal stratification' (Lucas, 2001) within higher education is widely acknowledged, far less attention has been applied to horizontal stratification within compulsory schooling.

We know that working class and middle class pupils tend to study different school subjects (Henderson, Sullivan, Anders, \& Moulton, in press). Even within subjects the curriculum followed is likely to differ, and is often structured by streaming and tiering (Gillborn \& Youdell, 2000). Alongside socio-economic differentials, gender segregation of subjects studied has persisted despite girls' increased absolute levels of educational attainment. Girls' and women's underrepresentation in STEM and overrepresentation in certain low-return vocational areas such as health and social care persists (Jin, Muriel, \& Sibieta, 2011). Subject specialisms also vary by ethnic group (Sullivan, Zimdars, \& Heath, 2010), yet the reasons for and consequences of this have rarely been examined.

In the English context, policy regarding the curriculum seems in some ways to have come full circle since the introduction of the national curriculum in 1988. The New Labour years saw a proliferation of 14-16 qualifications and subjects, and the removal of compulsory core subjects such as modern languages. This, combined with the structure of national league tables, incentivised schools to push qualifications of questionable value (Wolf, 2011). Subsequently, England has seen a return to a 'core curriculum', the scope of which is mandated by the EBacc (English Baccalaureate). Throughout all these changes, a lack of policy interest in evidence has been apparent. While the local policy context is quite specific, we see similar debates on the balance between a laissez-faire vs a prescriptive approach to the curriculum, both in the UK nations and internationally (Chmielewski \& Reardon, 2016).

This Special Issue aims to shed light on the causes and consequences of differences in the curriculum that different groups of pupils are exposed to. Quantitative and qualitative evidence is presented, from England, Wales, Scotland, Northern Ireland, and the Republic of Ireland, complemented by a philosophical contribution. A common theme running 
through the papers presented here is the question of whether curriculum differentiation exacerbates inequalities in the education system.

The first paper, by Richard Pring, provides a historical and critical overview of debates around the curriculum, and what the principle of equality may be taken to imply in this domain. Pring reminds us of the fact that selective school systems have historically been based on the assumption that different curricula were appropriate for different kinds of young people, and these assumptions should not be taken for granted. He points out that

The burden of proof lies on the shoulders of those who want to discriminate, rather than on the shoulders of those who want to pursue equal treatment for all ... those who wish to provide a different sort of schooling and curriculum for different pupils ... need to show how the differences in pupils themselves require differences in schooling and the curriculum.

He also points out that we cannot evaluate the success of the curriculum without an understanding of the end we have in mind: 'What counts as an educated person in this day and age?'.

The second paper, by Rhian Barrance and Jannette Elwood, reports on focus group data from Wales and Northern Ireland (NI). The paper explores what drives particular subject choices including a focus on assessment methods and how students experience different educational qualifications. Pupils' decisions are strongly influenced by the assessment methods used for qualifications, for example whether the qualification includes controlled assessments, coursework, or examinations, though the authors find that students do not always prefer the perceived easiest option. This paper highlights the differences that have emerged in education policy in the UK countries, including the fact that the EBacc subjects will be compulsory in England for all students from 2020, contrasting with Northern Ireland and Wales's policies to provide a'full range' of academic and vocational options at age 14-16. At the same time, there are country-specific compulsory subjects ('Learning for Life and Work' in $\mathrm{NI}$ and Welsh in Wales) which some pupils object to. A further source of variability is the nature and timing of GCSE assessments, and the use of 'tiering', which restricts access to elements of the curriculum within a given syllabus. Pupils expressed concerns about these country differences, as they thought their qualifications may not be perceived by employers as being as rigorous as English ones. Barrance and Elwood note that pupils are aware that their choices are restricted by schools, both through school subject selection procedures, and via the role of schools in pressuring pupils to pursue those subjects deemed appropriate for their perceived abilities. Pupils voiced the concern that the third year of secondary school was too early to make important choices about their futures which may restrict their future career options. Pupils also expressed discontent with schools' instrumental use of early entries, while the restriction on learning, grades, and future choices for those pupils placed in a lower tier was also a source of frustration.

Emer Symth's paper is a mixed-methods study, carried out in the Republic of Ireland. Young people in Irish schools have a choice between sitting their secondary school subjects at ordinary or higher level. Smyth finds that schools in fact constrain these choices, including via the use of streaming. The analysis of survey data presented in this paper shows that young people from working class backgrounds were less likely to take higher level subjects compared to their middle class peers even at the same level of prior attainment. The school context is also important, and individuals in schools with a high proportion of working class students were less likely to take higher level subjects. Interview data from case study schools vividly illustrate the way in which teachers' expectations and views regarding what 
constitutes an appropriate curriculum varied according to the socio-economic composition of the school. In middle class and socially mixed schools, teachers were more likely to promote higher level courses as the norm, whereas expectations were often managed downwards in working class schools. In addition, early subject 'choices' and stream allocations heavily constrained later options for young people. Smyth finds that the ceiling set on student achievement by differential success to higher level subjects, coupled with a climate of low expectations in working class schools and lower stream classes, has profound consequences for student outcomes and future options.

The next paper, by Cristina lannelli and Adriana Duta, analyses the influence of the subjects studied at school on young people's labour market outcomes, using the Scottish Longitudinal Study. Building on past research, which shows that taking academic subjects such as English, maths, sciences, and languages gives young people an advantage in the transition to higher education (lannelli, Smyth, \& Klein, 2015), this paper asks whether school subjects make a difference to early labour market outcomes for those young people who leave education either at the end of compulsory schooling or after two more years of education. The paper assesses the role of individual subjects at 'standard grade' level (age 16) and 'higher' level (age 18) rather than groups of subjects, and assesses whether there are differences in labour market outcomes three years later. The results suggest that subjects play a limited role for school leavers' labour market outcomes: only a few subjects seemed to provide an advantage either in avoiding unemployment or achieving a higher occupational status. History and business were linked to positive outcomes for lower secondary leavers, and maths for upper secondary leavers, controlling for background characteristics and prior attainment. For lower secondary leavers, overall attainment was clearly more important than subjects studied, whereas for upper secondary leavers, both attainment and subjects were approximately equally important.

Building on previous work demonstrating patterns of social class, gender, and ethnic differences in subjects taken by 14-16 year olds (Henderson et al., in press), the paper by Jake Anders, Morag Henderson, Vanessa Moulton, and Alice Sullivan examines the role of the school in producing curriculum differences using multi-level variance decomposition models applied to administrative data on young people in state schools in England. The results show that, while young people's socio-economic status and prior attainment are important, the school context matters over and above this. The composition of the school in terms of prior attainment and socio-economic status is influential in determining pupils' GCSE 'choices', and in fact, average socio-economic status (SES) in a school is as influential as individual SES in driving the choice of academically selective subjects. Pupils at single sex schools also tend to study a more selective curriculum. A third of the variation in subjects studied is explained by the school an individual attends. The wider local context is also important, as individuals in non-selective schools within selective areas (in other words, effectively secondary modern pupils in areas with neighbouring grammar schools) are less likely to study academically selective subjects, all other things being equal. The authors suggest that these findings highlight the fact that thinking about the subjects taken by pupils in terms of 'choice' is problematic, given that strong contextual constraints are apparent.

The paper by Vanessa Moulton, Alice Sullivan, Morag Henderson, and Jake Anders examines whether taking EBacc eligible subjects or applied subjects at 14-16 made a difference to transitions at 16-plus, both in terms of staying on in education, progressing to A-levels, 
and taking 'facilitating' subjects at A-level. The paper uses the Next Steps longitudinal study of young people in England. The authors find that students pursuing an EBacc-eligible curriculum at 14-16 had a greater probability of progression to all post- 16 educational outcomes, while taking an applied GCSE subject had a negative effect. There were no social class differences in the advantages of pursuing an EBacc-eligible or applied curriculum, which suggests that an academically demanding curriculum is just as advantageous for working class as it is for middle class pupils. Pursuing an EBacc-eligible curriculum increased the chances of educational progression particularly strongly for girls and white young people, while studying an applied subject especially decreased the chances of girls staying on. In particular, studying an EBacc-eligible curriculum at age 14-16 increased the chances of studying subjects favoured by selective universities at A-level.

Catherine Dilnot's paper develops a taxonomy of A-levels, based on the published preferences of the Russell Group of 24 high status UK universities, to categorise A-levels as 'facilitating', 'useful', and 'less suitable' for university entry. Using linked administrative data for three recent cohorts of English entrants to UK universities, she finds a strong association between taking facilitating subjects (especially maths) and entry to a high-ranking university, even controlling for prior attainment, degree subject, and other relevant factors. Similarly, 'less suitable' subjects are associated with attending a lower-ranked university, all else being equal, with a particularly strong penalty associated with taking law at A-level. Dilnot highlights the fact that young people choosing their A-level subjects may not be sufficiently well informed to take the subjects that will be most useful to them. For example, it is not obvious on the face of it that taking law at A-level may be damaging to the prospects of someone who aspires to do a law degree.

While the empirical contributions to this Special Issue are drawn from a range of contexts and use a range of methodological approaches, some common themes clearly emerge. First of all, social class matters in gaining access to highly-valued curricula, and this does not simply reflect differences in prior attainment. Class matters both at the individual level and at the institutional level, as working class pupils and pupils in working class schools are channelled into a less academic curriculum. Taken as a whole, the papers presented here problematise the notion that these differences are driven by individual 'choice'. Institutional constraints are central to the stories told by young people. Pring's paper reminds us of the justifications that were once used for providing a non-academic curriculum to secondary modern pupils, and Anders et al.'s paper suggests that, where selection is present, it still affects the curriculum offered by schools. But curriculum differentiation can also occur both between and within formally comprehensive schools, supported by the ubiquitous discourse of 'choice', rather than the old language of sheep and goats. Secondly, curriculum differences matter for educational transitions, even when overall attainment is taken into account. Subject 'choices' taken at a young age have the potential to cast a long shadow over young people's educational careers, a wrong turn taken in early adolescence leading to locked doors further down the road. However, social class differences in youth transitions are only partially accounted for by differences in the curriculum subjects that young people have taken, suggesting that equalising the subject curriculum in itself can only play a supporting role, rather than the lead part, in equalising educational opportunities.

The papers in this Special Issue highlight the level of policy divergence between the devolved UK countries, which creates great potential for comparative work assessing the impact of policy for young people. This could contribute to the development of evidence 
based policy within education, including on the curriculum, if policymakers have the appetite for it. As well as being evidence based, future policy needs to think through and take into account the potential unintended consequences of policy actions, especially the potential consequences for those who are already disadvantaged.

\section{Funding}

This work was supported by the CLS Cross Cohort Research Programme, ESRC grant number ES/M008584/1. Jake Anders' time on the project was supported by The Nuffield Foundation under grant number EDU/42169.

\section{ORCID}

Alice Sullivan (iD) http://orcid.org/0000-0002-0690-8728

Morag Henderson (iD http://orcid.org/0000-0003-0107-4899

Jake Anders (iD http://orcid.org/0000-0003-0930-2884

Vanessa Moulton (iD http://orcid.org/0000-0001-7709-0786

\section{References}

Chmielewski, A. K., \& Reardon, S. F. (2016). Patterns of cross-national variation in the association between income and academic achievement. AERA Open, 2, 1-27.

Gillborn, D., \& Youdell, D. (2000). Rationing education: Policy, practice, reform and equity. Buckingham: Open University Press.

Henderson, M., Sullivan, A., Anders, J. D., \& Moulton, V. (in press). Social class, gender and ethnic differences in subjects taken at age 14. Curriculum Journal.

lannelli, C., Smyth, E., \& Klein, M. (2015). Curriculum differentiation and social inequality in higher education entry in Scotland and Ireland. British Educational Research Journal, 42, 561-581.

Jin, W., Muriel, A., \& Sibieta, L. (2011). Subject and course choices at ages 14 and 16 amongst young people in England: Insights from behavioural economics. London: Department for Education, DfE Research Reports.

Lucas, S. R. (2001). Effectively maintained inequality: Education, transitions, track mobility, and social background effects. American Journal of Sociology, 106, 1642-1690.

Pring, R. (1972). Knowledge out of control. Education for Teaching, 89, 19-28.

Simon, B. (1976). Contemporary problems in educational theory. In B. Simon (Ed.), Intelligence, psychology and education: A Marxist critique (pp. 264-281). London: Lawrence and Wishart.

Sullivan, A., Zimdars, A., \& Heath, A. F. (2010). The social structure of the 14-16 curriculum in England. International Studies in Sociology of Education, 20, 5-21.

Wolf, A. (2011). Review of vocational education: The Wolf report (DFE-0031). London: Department for Education.

Young, M. F. D. (Ed.). (1971). Knowledge and control: New directions for the sociology of education. Durham: British Sociological Association.

Young, M. F. D. (1999). The curriculum of the future: From 'new sociology of education' to a critical theory of learning. London: Falmer Press. 